\title{
Performance Evaluation of a Standalone Solar PV System for Electricity Generation in an Estate
}

\author{
Richard Eberechi Echendu and Hachimenum Nyebuchi Amadi
}

\begin{abstract}
This work focuses on the performance evaluation of a Standalone Solar Photovoltaic (PV) system for electricity generation in an estate requiring a daily power consumption of 50KW. This was achieved through a solar tracker software/hardware - embedded programme control system. A programmable microcontroller (PIC16F877A), light detection sensors (CDS NORP 12), motor driver IC (L293D), power relays (NTE-R22-5) and a dc gear motor with linear actuator (HARL-3618) were used. MikroC Pro compiler from Mikro Electroniker was used to programme the PIC16F877A. A fixed PV panel of same size was placed side by side and tested with the solar tracking system. The test results obtained showed that the solar tracking system produced $14.3 \mathrm{~W}$ at 8:00am, increases to a maximum of $25.83 \mathrm{~W}$ at $1: 00 \mathrm{pm}$ and decreased to $16.28 \mathrm{~W}$ at 6:00pm while the fixed $P V$ panel produced $5 \mathrm{~W}$ at 8:00am, increased to a maximum of $25.62 \mathrm{~W}$ at $1: 00 \mathrm{pm}$ and decreased to $10.6 \mathrm{~W}$ at $6: 00 \mathrm{pm}$. These results gave the solar tracking system an efficiency increase of 33 percent over the fixed system. The designed system installed in residential homes has capacity to guarantee sustainable, durable and improved power supply.
\end{abstract}

Index Terms - Solar Energy; Single Axis Solar Tracker; PV Sizing; Microcontroller; DC Drives.

\section{INTRODUCTION}

The Photovoltaic (PV) is a device that consists of semiconductor material which is able to directly convert the energy from sunlight into electricity. In general, we have two main categories of photovoltaic systems namely Gridconnected and Standalone systems. Grid-connected systems are those PV systems that are linked or connected to the public or national grid, whereas standalone PV system has no connection or link to the grid system. Standalone PV system is usually used in rural or remote areas of the society. This system usually consists of some components: solar panel, batteries and controller/regulator. When AC supply is needed, an inverter circuit is required to convert the DC power to AC power. The charge controller is equally important, especially to control the charging process to prevent the batteries from excessive charging or discharging. During the day solar panel supply the energy both to the loads and batteries and then during the night all energy needed by the load is fully supplied by the battery bank. Reference [1] presented a sun tracking system incorporating a pyrheliometer for the measurement of direct solar radiation. The system which was controlled by a

Published on May 20, 2018

R. E. Echendu was with the Department of Electrical and Electronic Engineering of the Federal University of Technology, Owerri, Nigeria (email: eberechieche@yahoo.com).

H. N. Amadi is with Department of Electrical and Electronic Engineering of the Federal University of Technology, Owerri, Nigeria (amadihachy@gmail.com). closed-loop servo system had a four-quadrant photo detector to sense the sun's position and two small DC motors to drive the instrument platform such that the sun's image remained at the center of the four- quadrant always. Reference [2] studied the effects of four different electro-mechanical sun tracking systems on the current, voltage and power characteristics of a flat-plate photovoltaic system. The findings showed that tracking systems which incorporated two axes, one vertical axis, one east- west axis and one north- south axis, and one north- south axis, resulted in the increment of the electrical output powers of the photovoltaic system by $43.87 \%, 37.53 \%, 34.43 \%$ and $15.69 \%$ respectively when compared to what obtained from a PV system with fixed surface inclined at 32 degrees to the north. Reference [3] deployed a programmable logic controller (PLC) to effect the control of a photovoltaic module while tracking the sun's radiation. The work demonstrated that by collecting, storing and using sun's radiation related data to control a photovoltaic module, the daily output of the PV system could be significantly improved by more than $20 \%$ when compared to what obtained from a fixed module. Reference [4] designed and simulated three sun tracking systems, namely: (1) one - axis sun tracking with the tilted aperture equal to the latitude angle, (2) equatorial two- axis sun tracking, and (3) azimuth/elevation sun tracking. For each tracking system, the modeling and controller design tasks were accomplished using the first- order Sugeno fuzzy inference system.

Reference [5] presented a micro controller-based sun positioning system for hybrid lighting applications in which the celestial bearing of the sun with respect to the earth was computed directly from knowledge of the time, date, latitude, longitude and time zone information. Reference [6] developed an electro-mechanical, two axis tracking system in which the motion of the sun tracking surface was controlled by an open-loop control algorithm implemented using a PLC unit. The proposed system incorporated two separate tracking motors, namely one motor to rotate the sun tracking surface about the horizontal north- south axis, i.e. to adjust the slope of the surface and the other to rotate the sun tracking surface about the vertical axis, i.e. to adjust the azimuth angle of the surface. The experimental results indicated that the two - axis tracking system increased the total daily energy collection by approximately $41.34 \%$ compared with that obtained from a fixed surface tilted at 32 degrees towards the south. Reference [7] presented a simple step-by-step procedure for implementing a solar position algorithm. In the work, the solar zenith, azimuth and incidence angles were derived using ecliptic longitude and latitude for mean Equinox of date, apparent right ascension and apparent declination, together with notations in 
longitude, obliquity, obliquity of ecliptic and true geometric distance. The findings demonstrated that solar zenith and azimuth angles could be calculated with uncertainties of \pm 0.0003 degrees.

References [8] and [9] introduced general sun tracking formulas for open-loop type of sun tracking system useful for solving problems involving arbitrarily oriented sun tracking axes for both off-axis and on-axis solar collectors. Reference [10] presented a Micro Computer-based solar tracking and control system (TACS) capable of maintaining the peak power position of a photovoltaic (PV) array by adjusting the load on the array for maximum efficiency and changed the position of the array relative to the sun.

There are many standalone PV systems that have been installed in Nigeria, but all are fixed either on the roof of a building, at the top of an iron pole or other unmovable positions. These installations are of the fixed standalone PV system. They do not produce required maximum energy conversion as a result of the movement of the sun in the sky. This major problem of low energy conversion efficiency is what this project is set to solve using automatic sun tracking system. At present, PV energy conversion efficiency stands at between 9 to $18 \%$ depending on the solar cells used, especially in low irradiation conditions. It has also been established that the amount of electric power generated by PV arrays varies continuously with weather conditions. Even under clear weather conditions (steady amount of solar radiation) the position of the sun changes in the day, which leads to changes in the effective surface of the fixed solar panels towards the sun and a decreased output power.

For any PV system, one option to increase the energy produced by solar panels is solar tracking. The major problem is to develop a solar tracking system with the ability to direct solar panels continuously in optimal position to the sun, thus improving the overall efficiency of a PV system. This problem will be addressed in this project by using a programmable intelligent computer (PIC) which will receive analogue signals from positioned LDR sensors, analyze it and thus actuate the electric gear motor to move the solar panels into a position where maximum sunlight will be received.

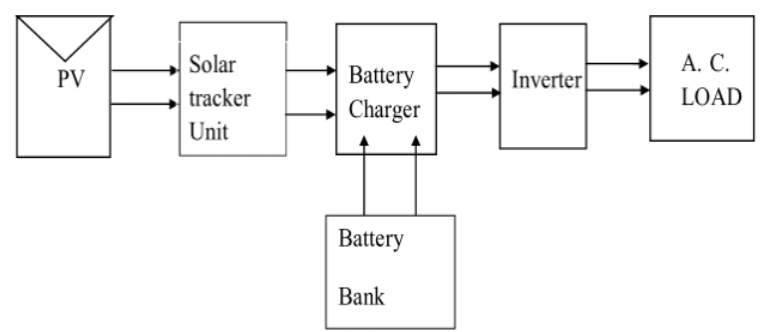

Fig. 1. Block diagram of the proposed system

The present work will design a standalone Solar PV system capable of generating an output power of $50 \mathrm{KW}$ to an estate. A tilted single axis solar tracker system will be constructed and incorporated to improve the power generation efficiency of the PV panels. A scale model of the system will be developed using a PV panel of size SSP20W. The solar tracking system will incorporate sensors, electric gear motor with linear actuator, relay drive circuit, PIC16F877A microcontroller, hardware and software designs.

\section{METHODOLOGY}

This section describes the design and evaluation the Standalone Solar Photovoltaic (PV) system.

\section{A. Site Data}

In this study, Nkpor Village near Port Harcourt, Nigeria (See Table I) was selected as the site for installation of the Solar Tracking PV System and the weather data used was supplied by Simba Solar, Abuja as was obtained from the NASA Langley Research Centre and GAISMA Research Centre, Finland (See Table II).

TABLE I: GEOGRAPHICAL PROFILE OF NKPOR VILlage, NEAR PoRT HARCOURT, NIGERIA ${ }^{1}$

\begin{tabular}{llll}
\hline \hline Latitude & Longitude & Time Zone & Altitude \\
\hline$+4.81\left(4^{\circ} 48^{\prime \prime 36 ” N)}\right.$ & $+7.01\left(7^{\circ} 00^{\prime 3} 36^{\prime E}\right)$ & UTC +1 Hour & $\sim 460 \mathrm{~m}$ \\
\hline \hline
\end{tabular}

TABLE II: PORT HARCOURT SOLAR ENERGY AND SURFACE METEOROLOGY ${ }^{1}$

\begin{tabular}{|c|c|c|c|c|c|c|c|c|c|c|c|c|}
\hline Variable & Jan & Feb & Mar & Apr & May & Jun & Jul & Aug & Sep & Oct & Nov & Dec \\
\hline $\begin{array}{l}\text { Installatio } \\
\mathrm{n}, \\
\mathrm{Kwh} / \mathrm{m}^{2} / \mathrm{d} \\
\text { ay }\end{array}$ & 5,78 & 5,87 & 5,43 & 5,09 & 4,47 & 4,36 & 3,89 & 3,79 & 3,96 & 4,27 & 4,89 & 5,41 \\
\hline $\begin{array}{l}\text { Clearness, } \\
0-1\end{array}$ & 0,61 & 0,59 & 0,52 & 0,49 & 0,47 & 0,44 & 0,39 & 0,37 & 0,39 & 0,43 & 0,51 & 0,59 \\
\hline $\begin{array}{l}\text { Temperatu } \\
\text { re, }{ }^{\circ} \mathrm{C}\end{array}$ & $\begin{array}{c}25,4 \\
3\end{array}$ & $\begin{array}{c}25,8 \\
6\end{array}$ & $\begin{array}{c}25,8 \\
1\end{array}$ & $\begin{array}{c}25,7 \\
7\end{array}$ & $\begin{array}{c}25,6 \\
7\end{array}$ & $\begin{array}{c}24,7 \\
5\end{array}$ & $\begin{array}{c}24,0 \\
4\end{array}$ & $\begin{array}{c}23,9 \\
4\end{array}$ & $\begin{array}{c}24,1 \\
5\end{array}$ & $\begin{array}{c}24,4 \\
4\end{array}$ & $\begin{array}{c}24,6 \\
8\end{array}$ & $\begin{array}{c}24,7 \\
3\end{array}$ \\
\hline $\begin{array}{l}\text { Wind } \\
\text { Speed, } \mathrm{m} / \mathrm{s}\end{array}$ & 2,75 & 2,97 & 2,71 & 2,39 & 2,23 & 2,81 & 3,21 & 3,37 & 2,96 & 2,35 & 2,25 & 2,4 \\
\hline $\begin{array}{l}\text { Precipitati } \\
\text { on, mm }\end{array}$ & 3,6 & 6,7 & 149 & 200 & 252 & 295 & 359 & 318 & 382 & 288 & 100 & 32 \\
\hline $\begin{array}{l}\text { Wet Days, } \\
\text { d }\end{array}$ & 3,2 & 5,4 & 10 & 13,2 & 15,9 & 17,7 & 20,4 & 20,4 & 21,6 & 17,1 & 7,4 & 3,3 \\
\hline
\end{tabular}

\section{B. Scale Modeling}

Scale modeling is the representation or copy of an object larger or smaller than the actual size of the object that maintains the relative proportion (scale factor) of the physical size of the original object. Scale model is usually smaller than the actual object but is used as a guide to making the full size. Researchers build scale models to test the likely performance of a particular design at the starting stage of their project in order not to incur the total expenses of the full prototype size. PV system is a modular project which can be built by either connecting the chosen PV panels in series to increase the output voltage or in parallel to increase the output current respectively. Due to the high cost of PV Panels and its accessories for a PV system, this work adopted and built a scale model prototype that is 2500 times smaller than the designed full-size PV system (2500:1 ratio).

Let the actual daily power consumption $=50 \mathrm{KW}$.

Let the research prototype model $=20 \mathrm{~W}$

Therefore, the scaling factor $X=1 / 2500=0.0004$ (This scale factor was used to determine the sizes of all the components of the model).

\section{Electrical Load Estimation}

The equipment that consume the generated power by the

${ }^{1}$ Source: Authors (2014) 
solar PV system are referred to as the load. The load in this project is household equipment such as televisions, Fans, Refrigerators, Lights, water Pumps, computers, phones etc. To accurately size the PV system, a load profile was constructed which was used to calculate the total energy demand per day. See Appendix 1 in the Appendices section of this work for details.

\section{Sizing the Standalone PV System}

The PV system was sized to decide the number and type of solar panels required, the capacity of the battery that will store the required energy and to also determine the required characteristics of other elements to be integrated in the system such as charge controller, power inverter and other Balance-of-System (BOS) components. To determine or ascertain a good measure of the reliability of the system, the number of days of autonomy was decided as 3 . The design method considered the energy requirements of the estate, as to size the elements of the standalone photovoltaic system that will provide a balance between cost and reliability. There are several ways of calculation to ensure reliability at a minimum cost, but they require a lot of statistical data of solar radiation that are scarce in many regions. It is on this note that a simple method known as the "Watt-Hour (WH) method" is proposed for this project. The method calculated the dimensions of the standalone system so that it can work effectively in the month of high demand of energy than the solar energy available. The reliability of the system was considered by fixing the maximum number of days it can work without receiving solar radiation, when energy consumption solely depends on the battery bank. The climate of the village and the type of installation determined the choice of the maximum number of days of autonomy (N). It was also noted that a higher number of $\mathrm{N}$ would require more components or investment; hence the number was chosen as 3. See details in Appendix 4 to this work.

\section{E. Solar Tracking System}

A solar tracking system is a support platform that orients or directs solar photovoltaic panels towards the sun's movement from dusk to dawn, hence maximizing solar energy power generation efficiency. There are two classes of trackers namely passive and active which may be constructed to track either in single or dual axis. The single axis trackers usually have a single axis tilt movement, while the dual axis trackers move in regular intervals adjusting for an angular position. Comparatively, the single axis trackers improve solar power production by about 20 to 30 percent with respect to a fixed tilted PV while dual axis trackers improve solar power production from 30 to 40 percent.

The solar tracker for this project is of the active class, single axis tracking mode. It consists of Tilted tripods, Panel mounts, Electric gear motor with linear actuator, Light intensity sensors, Drive and Controller circuits.

\section{F. Solar Panel Orientation and Tilt}

Azimuth is the angle of the sun along the horizontal plane with 0 degrees corresponding to the North, 90 degrees east, 180 degrees south and 270 degrees west. It can also be said as the angle in the horizontal plane between South and the horizontal projection of the Sun's rays East (positive +ve for eastern hemisphere) and West (negative -ve for Western Hemisphere) of South Pole. The solar noon is said to be the highest position of the sun as it moves in a curve- like manner across the sky. The solar noon is different from 12:00 o'clock noon or midday time. The solar noon occurs between 12:00 o'clock and 14:00 o'clock depending upon the location. Solar panel orientation refers to the azimuth setting. It has been proved that solar panel or solar array captures more energy when facing the sun directly. When the best azimuth angle is determined, the next key parameter to producing improved electricity from the sun is to determine the best elevation angle of the PV panel.

The solar azimuth, $\psi$, which is also called the bearing angle, is the angle in the horizontal plane between the observer's meridian plane and the meridian plane containing the sun. In general, the equation for solar azimuth angle, $\psi$, is given below:

$\sin \psi=\frac{\cos \delta \sin w}{\cos \alpha}$

Or

$\cos \psi=\frac{(-\sin \delta \cos \phi+\cos \delta \sin \phi \cos w)}{\cos \alpha}$

where

$\delta=$ declination angle

$\mathrm{W}=$ hour angle

$\alpha \quad=$ altitude angle

$\phi \quad=$ geographical latitude of the location

The location of this experiment is Nkpor Village, near Port Harcourt with geographical latitude of $4.81^{\circ} \mathrm{N}$.

The experiment was carried out on the $21^{\text {st }}$ of October, 2014 from 8.00am to $6.00 \mathrm{pm}$. To determine the Azimuth angle, $(\psi), \delta$, w and $\alpha$ were calculated using their formulas as follows:

\section{1) Calculation of $\delta$}

$$
\begin{aligned}
& \delta=23.4 \sin \left[\frac{360}{365}(284+d n)\right] \\
& \delta=23.4 \sin \left[\frac{360}{365}(284+294)\right]
\end{aligned}
$$

$\delta=23.4 \sin (570.082)$

$$
=-11.754^{\circ}
$$

(where $d n$ is the day of the year from January $1^{\text {st }}$ to December $31^{\text {st }}$. For October $21^{\text {st }}$, dn $=21+273=294$ days)

\section{2) Calculation of $w$}

$$
w=\cos ^{-1}(-\tan \phi \tan \delta)
$$




$$
\begin{aligned}
& =\cos ^{-1}[-0.0841 \times(-0.2081)] \\
& =\cos ^{-1}(0.01750896) \\
& =88.99^{\circ}
\end{aligned}
$$

\section{3) Calculation of $\alpha$}

$$
\alpha=\cos ^{-1}\left[\cos ^{2} \delta \sin ^{2} w+(\cos \phi \sin \delta-\sin \phi \cos \delta \cos w)^{2}\right]^{\frac{1}{2}}
$$$$
=\cos ^{-1}\left[\cos ^{2}(-11.754) \sin ^{2} 88.99+\left(\cos 4.81^{\circ} \sin (-11.754)\right.\right.
$$$$
\left.\left.-\sin 4.81 \cos ^{-1}(-11.754) \cos 88.99\right)^{2}\right]^{\frac{1}{2}}
$$$$
=\cos ^{-1}[0.9585 \times 0.99968+(0.99647 \times-0.2037-
$$$$
\left.0.08385 \times 0.979 \times 0.0176)^{2}\right]^{\frac{1}{2}}
$$$$
=\cos ^{-1}\left[0.9582+\left(-0.20298-1.4476 \times 10^{-3}\right)^{2}\right]^{\frac{1}{2}}
$$$$
=\cos ^{-1}[0.9582+0.04179]^{\frac{1}{2}}
$$$$
=\cos ^{-1} 0.999995
$$

$\alpha=0.18^{\circ}$

\section{4) Calculation of Solar Azimuth, $\psi$}

$$
\begin{aligned}
& \psi=\sin ^{-1}\left[\frac{\cos \delta \sin w}{\cos \alpha}\right] \\
& \psi=\sin ^{-1}\left[\frac{\cos (-11.754) \sin 88.99}{\cos 0.18}\right] \\
& \psi=\sin ^{-1}\left[\frac{0.979 \times 0.9998}{0.9999}\right] \\
& \psi=\sin ^{-1}(0.9789) \\
& \psi=78.2^{\circ}
\end{aligned}
$$

\section{G. Microcontroller}

For automatic control of the tracker and solar movement, a microcontroller system is required. This work deployed the microcontroller PIC16F877A.

\section{H. The DC Motor Control and Drive Circuit}

The drive unit consists of a 370W, 48V DC motor driving a $100 \mathrm{KN}$ screw jack linear actuator. The actuator rotates the PV through pushrod and multiple lever arms attached to a row of PV modules. To control the direction and speed of the DC motor used for the tracking system, a drive circuit was interfaced between the microcontroller and the $\mathrm{dc}$ motor. The drive circuit used is L293D motor driver IC. L293D is a typical motor driver IC which allows a DC motor to drive on either direction. The L293D is a 16 pin IC and is capable of controlling a set of two DC motors simultaneously in either direction. L239D operates on the principle of H-bridge, allowing the required voltage to flow in either direction. In a single L293D chip, there are two hbridge circuits that can rotate two dc motor independently.

\section{Light dependent resistor}

Light dependent resistor or LDR was chosen as the sensor because of its sensitiveness to light. The resistance of LDR decreases with increasing incident light intensity. LDR is used in this project to detect the direction of the sunlight.

\section{J. Inverter}

A power inverter device converts DC sources to AC sources. There are three different types of waveform output, namely Square wave, Modified sine wave and Pure or true sine wave. The Pure Sine wave inverter though more expensive than the other types of Inverters, was used in this work because it has the unique advantage that it produces waveforms which are the same as the power delivered by the utility grid.

\section{K. Batteries}

The batteries used in this PV system was for the purpose of storing the solar energy captured by the PV panels during the day, and to release the energy to the electrical load at night when there is no solar radiation. Batteries are needed because of the unreliable nature of the output being delivered by the PV panels.

\section{The Simulation System}

The Solar Tracker Control System was implemented through simulation. The simulation process was carried out using the Proteus Professional Software version 8.1. Appropriate components were selected from the Proteus Library and used. The outputs of the sensor circuits were connected to pins 2, 3 and 4 of the Microcontroller. Pins 33 and 34 of the microcontroller were connected to the input ports 2 and 7 of the motor driver. Pins 3 and 6 are the output ports of the motor driver that controls the directions of the motor movement. Digital AVO meter and current probe were used in measuring the open circuit voltage and the short circuit current of the PV panels respectively. The results of the fixed and the tracking system are as recorded below. The simulation diagram of the solar tracking control system is shown in Fig. 2.

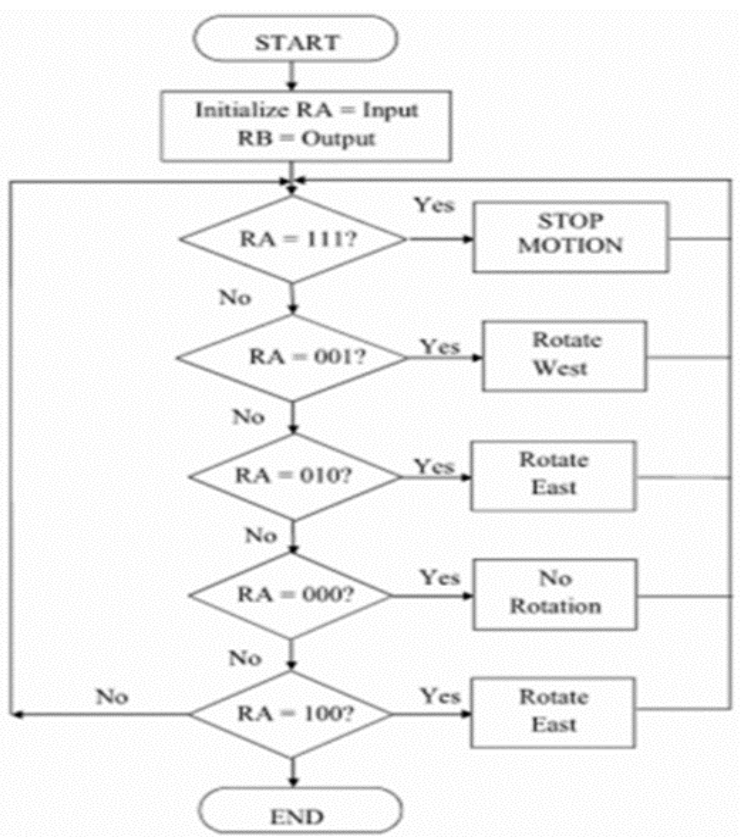

Fig. 2. Flow Chart of PIC16F877A programming 


\section{RESULTS AND DISCUSSIONS}

The experimental results obtained have shown that the solar tracking system produced 33 percent daily output power than the fixed PV system. This is a demonstration of the performance ability of solar tracking system. This is a confirmation or proof that the designed single axis solar tracking standalone PV system will generate the required output power of $50 \mathrm{KW}$ for the rural estate. To analyze and evaluate the results obtained (See Table III), the daily average values measured at the output of the PV panel (module) of both the fixed and tracking system was calculated as follows:

\section{A. Fixed PV System}

Average value of current,

$$
I=\frac{10.87}{11}=0.988 A
$$

Average value of voltage,

$$
V=\frac{168.19}{11}=15.29 \mathrm{~V}
$$

Output power,

$$
P_{f}=V I=0.988 \times 15.29=15.1 W
$$

\section{B. Single Axis Tracking System}

Average value of current,

$$
I=\frac{11.68}{11}=1.06 A
$$

Average value of voltage,

$$
V=\frac{208.71}{11}=18.97 \mathrm{~V}
$$

Output power,

$$
P_{f}=V I=1.06 \times 18.97=20.1 W
$$

The efficiency of the single axis tracking system over that of the fixed system, the power gain $\left(G_{p}\right)$ is calculated as follows:

$$
\begin{aligned}
& G_{p} \%=\{(\text { Power obtained by tracking mode }- \text { Power } \\
&\text { obtained by fixed mode }) / \text { Power obtained by fixed } \\
&\text { mode }\} \times 100 \% \\
& \\
&=[(20.1-15.1) / 15.1] \times 100 \% \\
&=33 \%
\end{aligned}
$$

This result shows that the prototype single axis tracking system increased energy production by $33 \%$ compared to the fixed PV system. Photovoltaic panels have been in use in our country, Nigeria but with much failure because the contractors who install them have little or no experience over PV systems. The common practice is to install a fixed PV system either on the roof top, on electric poles, mounted pillars etc. The mounted PV panels are positioned horizontal, vertical or tilted. These fixed positions produce

\begin{tabular}{|c|c|c|c|c|c|c|}
\hline \multicolumn{4}{|c|}{ Fixed Panel } & \multicolumn{3}{|c|}{$\begin{array}{c}\text { Solar Tracking System } \\
\text { (Single-Axis) }\end{array}$} \\
\hline $\begin{array}{l}\text { Time/Hour } \\
\text { of the Day }\end{array}$ & $\begin{array}{l}\text { Open } \\
\text { Circuit } \\
\text { Voltage } \\
\text { (V) }\end{array}$ & $\begin{array}{l}\text { Current } \\
\text { (A) }\end{array}$ & $\begin{array}{l}\text { Power } \\
\text { (W) }\end{array}$ & $\begin{array}{l}\text { Open } \\
\text { Circuit } \\
\text { Voltage } \\
\text { (V) }\end{array}$ & $\begin{array}{l}\text { Current } \\
\text { (A) }\end{array}$ & $\begin{array}{l}\text { Power } \\
\text { (W) }\end{array}$ \\
\hline 8:00AM & 10 & 0,5 & 5 & 16,82 & 0,85 & 14,4 \\
\hline 9:00AM & 10,7 & 0,92 & 9,84 & 17,11 & 0,97 & 16,6 \\
\hline 10:00AM & 11 & 0,95 & 10,85 & 18 & 1,05 & 18,9 \\
\hline 11:00AM & 16,8 & 1,05 & 17,65 & 18,6 & 1,09 & 20,27 \\
\hline 12:00PM & 19,88 & 1,1 & 21,87 & 20,3 & 1,13 & 22,94 \\
\hline 1:00PM & 21 & 1,22 & 25,62 & 21 & 1,23 & 25,83 \\
\hline 2:00PM & 19,96 & 1,15 & 22,95 & 20,9 & 1,16 & 24,25 \\
\hline 3:00PM & 17,85 & 1,04 & 1856 & 20,6 & 1,12 & 23,1 \\
\hline 4:00PM & 16,8 & 1,02 & 17,1 & 19,86 & 1,08 & 21,45 \\
\hline 5:00PM & 12,9 & 0,97 & 12,5 & 18,56 & 1,04 & 19,3 \\
\hline 6:00PM & 11,3 & 0,94 & 10,6 & 16,96 & 0,96 & 16,28 \\
\hline Average $\mathbf{P c}$ & er $(W)$ & & 15,1 & & & 20,1 \\
\hline
\end{tabular}
very low electric power from the sun as the sun moves from the east to the west of the globe every day.

The output power efficiency of the solar panels was improved by the tracking facilities designed to track the sun from sunrise to sunset at a position of maximum power output. The position of maximum power output was achieved anytime the solar panel is perpendicular to the sun.

TABLE III: THE RECORDED DATA OF VOLTAGE, CURRENT AND POWER FrOM THE FiXed SOlar PANEL AND THE SOlar TRACKING PV SySTEM FOR THE SAME DAY ${ }^{2}$

Fig. 3 is the graphical presentation of the output power for both the fixed PV panel and the tracking PV panel against time. It illustrates improvement in efficiency achieved using solar tracking system. In Fig. 3, the solar intensity increased with day time to a maximum at $1.00 \mathrm{pm}$ when it starts decreasing. There was fluctuation of intensity due to flow of some cloudy sky and abnormal atmospheric condition. It was also noticed that both the fixed and tracking output values are the same at $1.00 \mathrm{pm}$; this is because the sun at this time is perpendicular to both the fixed and the tracking panels.

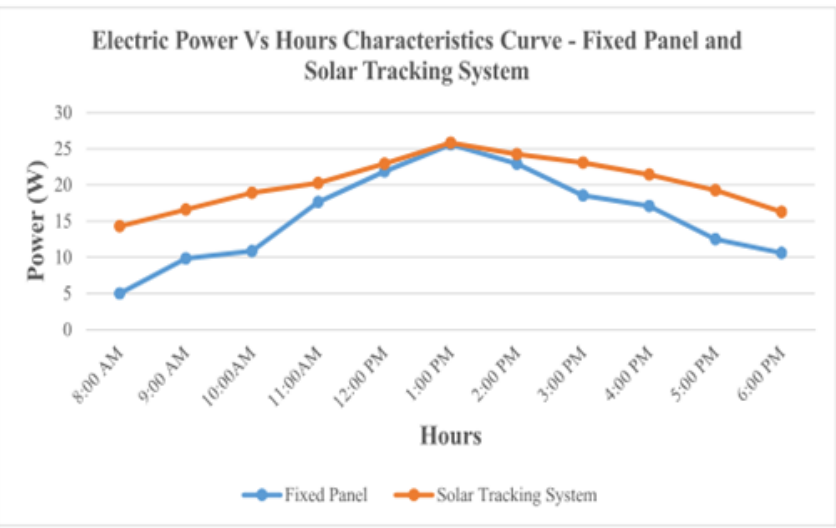

Fig. 3. Electric Power Vs Time Characteristics Curve - Comparison of Single Tracking and Fixed Panel Systems 


\section{CONCLUSION}

The aim of this work was to design, construct and evaluate the performance of a standalone solar tracking PV system for a residential estate requiring a load power of $50 \mathrm{KW}$. To achieve this goal, the sizing of the PV system was first carried out with the parameters of the PV panels and batteries determined. The second step was to design the mechanical components of the solar tracker. The third step was to determine the cost of the PV panels and batteries, which was very exorbitant, hence it was agreed that a prototype of the system be constructed and used to reduce cost. A scale modeling was carried out with the full size components being multiplied by a scaling factor of 0.0004 . The resultant PV panel size used for the prototype construction is 20Watts.

An automatic single axis solar tracker was designed, built and tested. The automatic solar tracker system is microcontroller based. The PIC16F877A microcontroller was chosen, a high level programming language Mikro Pro was utilized. The microcontroller receives analog signals from the sensors via a comparator circuit, processes it and sends the signals in digital form to drive and control the DC gear motor via a drive circuit. The utilized control system made the sun tracking by the PV panel easy and automatic without manual adjustments.

An experimental test was carried out under the same meteorological conditions and time for a fixed solar panel and solar tracking system both of the same capacity of 20Watts. Test results obtained showed that the output power of the solar tracking system increased with daytime- hours from $14.3 \mathrm{~W}$ at $8.00 \mathrm{am}$ to a maximum of $25.83 \mathrm{~W}$ at $1.00 \mathrm{pm}$ but decreased to $16.28 \mathrm{~W}$ at $6.00 \mathrm{pm}$ while the fixed PV system gave a value of $5 \mathrm{~W}$ at $8.00 \mathrm{am}$, increased to $25.62 \mathrm{~W}$ at $1.00 \mathrm{pm}$ then decreased to $10.6 \mathrm{~W}$ at $6.00 \mathrm{pm}$. The results indicated that at $1.00 \mathrm{pm}$ the sun was perpendicular to both the solar tracking system and the fixed PV system.

The major outcome of this investigation is that solar tracking produced higher power outputs of about 33\% efficiency than fixed PV panels. The significance of the outcome is that, to produce a required electrical output power from a PV system, less PV panels will be required using solar tracking than fixed PV system. The performance of the solar tracking system proved that the required load power of $50 \mathrm{KW}$ for the estate can be achieved with lesser PV panels than theoretically designed with cost reduction.

\section{APPENDIX I}

ELECTRICAL LOAD ESTIMATE (A)

\begin{tabular}{|c|c|c|c|c|c|c|c|}
\hline \multirow{3}{*}{ Appliances } & \multirow{3}{*}{ 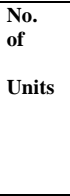 } & \multirow{3}{*}{$\begin{array}{l}\text { Unit } \\
\text { Rated } \\
\text { Wattage }\end{array}$} & \multirow{3}{*}{$\begin{array}{l}\text { A4 } \\
\text { Total } \\
\text { Rated } \\
\text { Wattage }\end{array}$} & \multirow{3}{*}{$\begin{array}{l}\text { A5 } \\
\text { Adjustment } \\
\text { Factor (A1) } \\
\text { for A.C. }\end{array}$} & \multirow{3}{*}{$\begin{array}{l}\text { A6 } \\
\text { Adjustment } \\
\text { Wattage } \\
\text { (A4/A5) }\end{array}$} & \multirow{3}{*}{$\begin{array}{l}\text { A7 } \\
\text { Hours } \\
\text { Per } \\
\text { Day }\end{array}$} & \multirow{3}{*}{$\begin{array}{l}\text { A8 } \\
\text { Energy } \\
\text { Per Day } \\
\text { (A6 x } \\
\text { A7) } \\
\end{array}$} \\
\hline & & & & & & & \\
\hline & & & & & & & \\
\hline Fans & 80 & 100 & 8000 & 0,85 & 9400 & 10 & 94000 \\
\hline Refrigerators & 20 & 100 & 2000 & 0,85 & 2350 & 20 & 47000 \\
\hline Bulbs & 160 & 20 & 3200 & 0,85 & 3765 & 12 & 45180 \\
\hline $\begin{array}{l}\text { Desktop } \\
\text { Computer }\end{array}$ & 20 & 70 & 1400 & 0,85 & 1647 & 5 & 8235 \\
\hline Laptops & 20 & 65 & 1300 & 0,85 & 1530 & 4 & 6120 \\
\hline DSTV & 20 & 30 & 600 & 0,85 & 706 & 12 & 8472 \\
\hline Water Pump & 4 & 750 & 3000 & 0,85 & 3530 & 0,5 & 1765 \\
\hline Iron & 20 & 1000 & 20000 & 0,85 & 23530 & 0,5 & 11765 \\
\hline Blender & 20 & 300 & 6000 & 0,85 & 7059 & 0,5 & 3530 \\
\hline $\begin{array}{l}\text { Phone } \\
\text { Charger }\end{array}$ & 60 & 20 & 1200 & 0,85 & 1400 & 2 & 2800 \\
\hline
\end{tabular}

\begin{tabular}{llll}
\hline \hline Total & 46700 & 54917 & 228867 \\
\hline \hline
\end{tabular}

\section{APPENDIX II}

A1 - Inverter efficiency $=85 \%$

LOAD SIZING (A)

A2 - Battery bus voltage $=48 \mathrm{~V}$

$\mathrm{A} 3$ - Inverter $\mathrm{AC}$ voltage $=220 \mathrm{~V}$

A9 - Total energy demand per day (Sum of A8) $228,867 \mathrm{WH}$

A10 - Total ampere hour demand per day $($ A9/A2) $=4768 \mathrm{AH}$

A11 - Maximum AC Power requirement (Sum of A4) $=46,700 \mathrm{~W}$

A12 - Maximum DC Power requirement $($ Sum of A6) $=5491 \mathrm{~W}$

\section{APPENDIX III}

BATTERY SIZING (B)

Design Temperature was $25^{\circ} \mathrm{C}\left(77^{\circ} \mathrm{F}\right)$

$\mathrm{B} 1$ - Number of days of autonomy $(\mathrm{N})=3$ Days

B2 - Allowable depth of discharge limit (decimal) $=0.8$

B3 - Required battery capacity $(\mathrm{A} 10 \times \mathrm{B} 1) / \mathrm{B} 2=4768 \times 3 / 0.8$ $=17880 \mathrm{AH}$

B4 - Amp-hour capacity of selected battery $=200 \mathrm{AH}$

B5 - Number of batteries in parallel $(B 3 / B 4)=17880 / 200=90$

B6 - Number of batteries in series (A2/Selected battery voltage) 48/12 $=4$

B7 - Total number of batteries $($ B5 $\times$ B6) $=90 \times 4=360$

B8 - Total batter Amp-hour capacity (B5 x B4) = 90 x 200 $=18000 \mathrm{AH}$

B9 - Total battery Kilowatt-hour capacity ((B8 x A2)/1000) $=18000 \times 48 / 1000=864 \mathrm{KWH}$

B10 - Average daily depth of discharge (0.75 x A10)/B8 $=0.75 \times 4768 / 18000=0.2$

\section{APPENDIX IV}

PV ARRAY SIZING (C)

Design Tilt (Latitude +15 degrees $)=4.81+15=20$ degrees

Design Month - August

C1 - Total energy demand per day $($ A9) $=228,867 \mathrm{WH}$

$\mathrm{C} 2$ - Battery round trip efficiency $=0.85$

C3 - Required array output per day (C1/C2) 228,867/0.85 $=269,255 \mathrm{WH}$

C4 - Selected PV module maximum power wattage at STC (x 0.85) $=30.45 \times 0.85=25.9 \mathrm{~V}$

C5 - Selected PV module guaranteed power output at STC $=230 \times 0.9=207 \mathrm{~W}$

C6 - Peak sun hours at design tilt for design month $=6$ Hours

C7 - Energy output per module per day $=($ C $5 \times$ C6 $)=207 \times 6$ $=1242 \mathrm{WH}$

C8 - Module energy output at operating temperature (D.F x C7) $=0.9 \times 1242=1118 \mathrm{WH}$

C9 - Number of modules required to meet energy requirements $(\mathrm{C} 3 / \mathrm{C} 8)=26269255 / 1118=241$ Modules

C10 - Number of modules required per string (A2/C4) $=48 / 25.9=2$ (Rounded to next higher integer)

C11- Number of strings in parallel $($ C $9 /$ C10 $)=241 / 2=120$ Strings

C12- Number of modules to be purchased $(\mathrm{C} 10 \times \mathrm{C} 11)=240$ Modules

C13- Nominal rated PV modules output $=230 \mathrm{~W}$

$\mathrm{C} 14$ - Nominal rated array output $(\mathrm{C} 13 \times \mathrm{C} 12)$ $=230 \times 240=55,200 \mathrm{~W}$

The design connection to achieve the required PV array output is as follows:

(i) Number of SPP $230 \mathrm{~W}$ PV Panels connected in series $=2$

(ii) Number of SPP $230 \mathrm{~W}$ PV Panels connected in parallel $=120$

For the AGM deep cycle storage batteries:

(i) Number of batteries in series $=4$

(ii) Number of batteries in parallel $=90$ 


\section{APPENDIX V}

PROTOTYPE DESIGN

From the scale modelling, the full-size components will be multiplied by a factor of 0.0004 PV Panel (D)

D1 - Number of required $230 \mathrm{~W}$ PV Panels $=50000 / 230=218$

D2 - Number of required $20 \mathrm{~W}$ PV Panels $=50000 / 20=2500$

D3 - Number of prototype panels $=2500 \times 0.0004$

D4 - Number of panels per string $=1$

D5 - Number of strings in parallel $=1$

D6 - Number of panels to be purchased (D4 x D5) = I Module

The electrical/mechanical characteristics of the PV panels are as follows:

Rated maximum power $(\mathrm{Pmax})=20 \mathrm{~W}$

Current at Pmax $=1.5 \mathrm{~A}$

Short circuit current (Isc)) $=1.28 \mathrm{~A}$

Open circuit voltage $(\mathrm{Voc})=21.8 \mathrm{~V}$

Weight $=2.5 \mathrm{Kg}$

Dimension = Length 530mm; Width $340 \mathrm{~mm}$; Depth $25 \mathrm{~mm}$

Battery

F1 - Ampere-hour capacity of selected battery $=100 \mathrm{AH}$

$\mathrm{F} 2$ - Number of batteries in parallel $=1$

F3 - Number of batteries in series $=1$

F4 - Required battery voltage $=12 \mathrm{~V}$

F5 - Total number of batteries required $=1$

\section{ACKNOWLEDGMENT}

The authors express their gratitude to the members of the Nkpor Village near Port Harcourt, Nigeria where the project was sited for the warm cooperation and to the Staff and Management of the Simba Solar, Abuja for supplying the necessary weather data used for the study.

\section{REFERENCES}

[1] P. Roth, A. Georgiev, and H. Boudinov, "Cheap two axis sun following device," Energy Convers Manage; 46: pp 1179- 1192, August 2004.

[2] S. Abdallah, "The effect of using sun tracking systems on the voltagecurrent characteristics and power generation of flat plate photovoltaics," Energ. Convers. Manage. Vol. 45, pp.1671-1679, May 2004.

[3] A. Al-Mohamad, "Efficiency improvements of photovoltaic panels using a sun-tracking system,” Appl. Energ. Vol. 79, pp. 345-354, July 2004.

[4] M. Alata, M.A. Al-Nimr, and Y. Qaroush, "Developing a multipurpose sun tracking system using fuzzy control," Energ. Convers. Manage. Vol. 46, pp 1229- 1245, February 2005.

[5] D.L. Beshears, G.J. Capps, D.D. Earl, J.K. Jordan, L.C. Maxey, J.D Muhs, and T.M. Leonard, "Tracking systems evaluation for the Hybrid Lighting System," In Proceedings of International Solar Energy Conference, Kohala Coast, HI, USA. July 2003.

[6] S. Abdallah, and S. Nijmeh, "Two axes sun tracking system with PLC control," Energ. Convers. Manage. Vol. 45, pp. 1931-1939, March 2004.

[7] I. Reda, and A. Andreas, "Solar position algorithm for solar radiation applications," Sol. Energ, Vol. 76, pp 577- 589, April 2004.

[8] Y.T. Chen, B.H. Lim, and C.S. Lim, "General sun tracking formula for heliostats with arbitrarily oriented axes," J. Sol. Energy. Eng. Vol. 128, pp 245-250, April 2006.

[9] K.K. Chong, and C.W. Wong, "General formula for one axis sun tracking system and its application in improving tracking accuracy of solar collector," Sol. Energy, Vol. 83, pp 298-305, September 2009.

[10] D.W. Hart, Introduction to Power Electronics, Prentice Hall, April 2007. 